\title{
Implementation of Roles and Functions of Case Managers
}

\author{
F Sri Susilaningsih ${ }^{1}$, Brylian Anindya Dayfi ${ }^{2}$, Kurniawan Yudianto ${ }^{3}$ \\ ${ }^{1,3}$ Faculty of Nursing, Universitas Padjadjaran, ${ }^{2}$ Akper SAMAWA Sumbawa \\ Email:f.sri@unpad.ac.id
}

Submitted: 02-08-2017 Accepted: 25-12-2018 Published: 31-12-2018

\begin{abstract}
Case management is an intervention strategy used by health care providers and systems to support clients, coordinate health services, and facilitate results in both price and quality. In this model of care, the case manager plays an important role in ensuring that the case management service flow is well implemented. This study aims to see how the role of case managers in carrying out their functions such as utility assessment, planning, facilitation and advocacy, service coordination, evaluation, and post-discharge follow-up. The research method used is the mixed method sequential exploratory design. This method explores the work experience of a case manager in the field, then composes a measuring instrument, and then seeks to quantify the role and function of the case manager. The population in this study was the case managers in the Kemuning and Fresia Building at Dr. Hasan Sadikin General Hospital Bandung amounting to 36 people. The research sample was divided into two, in the qualitative stage the number of participants as many as 5 people was determined by purposive sampling technique, and the quantitative stage used a total sampling of 36 people. The results showed that the qualitative analysis of the assessment function identified indicators of ability to collect data, analysis, and stratification of patients; in the planning function the ability to determine goals, take joint decisions and identify problems were identified; in the facilitation function and advocacy, the ability to be identified as an educator, protector of patient rights and solution provider were identified; in the service coordination function, the ability for team communication and communication between lines were identified; in the evaluation function the ability to evaluate patients and self-evaluation were identified; and in the post-discharge follow-up function the ability related to continuity of service was identified. In the implementation, the case manager carries out those functions, 4 functions are still carried out improperly by most respondents such as the joint decision making, team communication, patient evaluation, and self-evaluation.
\end{abstract}

Keywords: Case management, case manager, role and function. 
F Sri Susilaningsih : Implementation of Roles and Functions of Case Managers

\section{Introduction}

Improving the quality of services in hospitals is intended to change one's work culture, change the service process, and improve service outcomes. The target of the service outcome is the outcome of the patient's quality, professional outcome and economic outcome (Wijono, 2008). The transition of the service model from traditional to patient -centered care is one form of effort carried out to achieve good service quality. Patientcentered care is care that respects and is responsive to the choices, needs and personal values of the patient and ensures that value is a guide for clinical decisions (Aeni, 2014). Panel study experts agreed on a nursing model namely case management as an effort to realize the preference or the right of patients to determine treatment choices according to their needs and expectations (MoralesAsencio, 2010). Corresponding to this, Huber (2010) states, this philosophy has reached its time. Patient-centered case management is a model that is currently gaining popularity in all health services in the world.

Case management is an intervention strategy used by health-care providers and in health-care systems to support clients, coordinate health services, and facilitate results in both price and quality (AHC, 2016). In this model patients and families have the freedom to select services based on the patient's perspective and consideration of the patient's medical and non-medical conditions. The case management model requires a case manager with varying abilities and quality skills, namely someone who is creative with good communication skills. Case managers must be able to anticipate unexpected events and improve this by prioritizing health team collaboration without putting aside patients and families by not hearing and understanding what they expect (AHC, 2016). Professionally, the case manager has the ability to explore the patient's background and help both individually and in team by gathering information and sharing practices so as to help make the system function more efficiently.

A case manager must be able to carry out its functions, namely conducting assessments and case discussions, active interaction with patients, coordination with the patient's family and health professionals, and close coordination with the hospital. A study conducted by Elwyn, Williams, Roberts, Newcombe, and Vincent (2008), analyzed 121 cases of management by five APNs (Advanced Primary Nurse) as case managers during a period of 12 months. Of the 121 patients in the primary care setting, 73 of them have received very positive benefits from this case management approach. According to the case managers' perspective their intervention through this approach has not led to deterioration of any patient. The success of the 73 patients is due to the case manager's ability to carry out assessment functions and coordination of services as well as terminal service facilitation.

Based on the 2015 KARS guidelines on 'Guidelines for DPJP Management and Case Managers', there are six functions that must be carried out by the case manager, namely utility assessment, planning, facilitation and advocacy, service coordination, evaluation, and post-discharge follow-up (KARS, 2015). The guidelines are considered more relevant since they have been used as a guide by hospitals in Indonesia.

Based on interview results of the researcher with the building supervisor at Dr. Hasan Sadikin General Hospital Bandung (RSHS Bandung) during the field experience in December 2016, the building supervisor conveyed that the existence of the case manager at RSHS Bandung still had to be adjusted both in structure and function. Under whose control does the case manager work and what is the difference between the work of the case manager and other functions such as the Head Nurse, team leader, or with other care providers, so that the actual role and function of the case manager can be identified, implemented and evaluated. In line with the previous opinion, Nucki Nursjamsi Hidayat, the Medical and Nursing Director of RSHS Bandung, in a seminar entitled "Integrated Patient Care" in December 2016, stated that the position of the case manager is vital in the integrated pattern of patient care, since the case manager is a patient service manager (MPP) who is in charge of leading every professional careprovider (PPA) as well as being a liaison to the patient. The existence of 
F Sri Susilaningsih : Implementation of Roles and Functions of Case Managers

a case manager especially in RSHS Bandung must be supported and utilized. There are still some points that must be improved such as competency and also the optimization of the case manager's ability to carry out their roles and functions even though each case manager has been given training in this regard.

The previous opinions are in accordance with what is sensed by the case manager. Study results from Mamuaja, Tambun, and Kaunang (2016) state, there are difficulties faced by nurses in carrying out their roles and functions as a case manager due to lack of understanding and underlying knowledge. A functioning case manager will get better job satisfaction administratively, pride in what they receive, and have a positive impact on the organization (Lynn \& Kelley, 1997).

Paying attention to the phenomena captured in the background, the problem in this study is that the case manager functions have not been identified such as utility assessment, planning, facilitation and advocacy, service coordination, evaluation, and post-discharge follow-up at RSHS. Therefore the researcher was interested to find out about the implementation of the role and functions of the case manager at Dr. Hasan Sadikin General Hospital.

\section{Method}

This study used the mixed method sequential exploratory design (Creswell \& Clark, 2007). The study was conducted in three phases. The first phase was an exploratory study to obtain information about the implementation of the role and functions of the case manager. Information was obtained through in-depth interviews with 5 informants, namely nurse case manager with a professional education background from Ners (BSN +1 year internship program) and work experience of more than 10 years. The explored information through these depth-interviews focused on the case manager functions including utility assessment, case management plan, facilitation and advocacy, service coordination, service process evaluation both clinically and administratively, and postdischarge follow-up (patient is sent home or transferred). Analyses of the results of qualitative studies and literature reviews were used to determine indicators of case manager functions, which were then used to develop research instruments ( $2^{\text {nd }}$ phase of research). The instrument design was developed through the preparation of grids based on the indicators that were set in the previous stage; the content validity of the instrument contents was carried out by four panel experts. Then the construct test was conducted on 67 items from $6 \mathrm{sub}$-variables that had been through the content validity. A total of 48 items were valid and reliable, and represented the 6 sub-variables, so this instrument was used to collect the data quantitatively in the third phase of the study. In the third phase of the study, a survey was conducted on the implementation of case manager functions in the Kemuning inpatient surgery ward and Fresia internal medicine ward involving all the case managers who served in the two inpatient units, with a total of 36 nurse case managers. The quantitative descriptive data analysis was performed to determine whether the implementation of case manager functions in the six sub-variables above was appropriate or not, it was appropriate if the percentage of respondent answers was $\geq$ standard range, and not appropriate if < standard range (Sugiyono, 2010). The default range is the maximum percentage - interval. Maximum percentage $(100 \%)$, minimum percentage $(25 \%)$, range $(100 \%-25 \%=$ $75 \%)$, interval $(75 \%: 2=37.5 \%)$, standard range $(100 \%-37.5 \%=62.5 \%)$. So the implementation of the case manager function is appropriate if the percentage is $\geq 62.5 \%$, and is not appropriate if $<62.5 \%$.

\section{Result}

Analysis of qualitative data

Utility assessment, the theme related to the utility assessment was associated with the ability of a case manager in performing the process of collecting data regarding the clinical and social conditions of the patient. The analysis process aimed to see all the best needs and possibilities for patients. Participants' opinions regarding utility assessment functions were that in carrying out the utility assessment function there were 
F Sri Susilaningsih : Implementation of Roles and Functions of Case Managers

some qualities required of a case manager, such as the ability to collect data, and analyze data, and stratify patients.

Planning, the theme related to planning functions is how in this process the case manager prepares a patient care plan or commonly known as the case management plan. The case management plan is prepared jointly by involving patients, families, and caregivers in hospitals, payers, and others. The planning reflects the feasibility/ suitability, quality and cost effectiveness of clinical treatment and patient needs, including discharge planning. Participants' opinions regarding planning functions were revealed that in the implementation of the planning function there were three things that the case manager must have. Those were the ability to set goals, make collaborative decisions, and identify problems.

Facilitation and Advocacy, this function includes the interaction between the case manager and team members, contractors, management, and patients/families to maintain continuity of service. The case manager is also expected to represent the interests of patients by advocating for each treatment option that can be received in each line including the patient's return plan.

Participants' opinions regarding facilitation and advocacy functions were showed that in the implementation of facilitation and advocacy functions there were three factors that the case manager must possess, which were the ability to provide education, protect the rights of patients, and provide solutions.

Service Coordination is carried out to maintain the continuity of services and ensure the fulfillment of patient care needs. Such as medical care, nursing care, pharmaceutical care, nutritional care, and administrative care. This is carried out by building good communication between patients and the health team and related units. The objectives are to have a common understanding and action so as to minimize service fragmentation. The most important thing is to maintain harmonization and coordination among professional caregivers who remain intertwined. Opinions of participants regarding this function were showed that in the implementation of service coordination functions, each case manager must have good communication and coordination skills to each line.

Evaluation is carried out to conduct a thorough assessment of the treatment process clinically and administratively, in this case, to what extent is the case manager able to evaluate service utilization, clinical pathway implementation, including quality control and costs. Evaluation coverage starts from admission to discharge. The opinions of participants regarding this function were revealed that in the implementation of evaluation functions, each case manager must have the ability to conduct patient evaluations and self-evaluation.

Post-discharge follow-up, this theme discussed the case manager ability to provide certainty, clarity of time, and security when returning or transferring patients from one place to another. This was done by identifying each potential problem that would be faced by the patient when going home, identifying the patient's needs either simple or complex, as well as making a checklist for patients after being at home. Following were the participants' opinions regarding the postdischarge follow-up functions it revealed that the implementation of the post-discharge follow-up function was carried out to ensure the continuity of services in a safe and timely manner.

Quantitative Analysis

Utility Assessment, moreover, the distribution of respondents in the utility assessment function in Table 1 above informed, from the three indicators on the utility assessment, the case manager function was implemented appropriately by more than half of the respondents, which was the highest percentage of suitability in collecting data.

Planning, based on the distribution of respondents in the planning function in accordance with Table 3, it could be informed that in two indicators, namely the determination of objectives and identification of problems, the suitability of implementation was more than $50 \%$, while in the collaborative decision indicator, the suitability of implementation only reached $39 \%$. 
F Sri Susilaningsih : Implementation of Roles and Functions of Case Managers

Facilitation \& Advocacy, the information in Table 3 above, illustrated that of the three indicators on the facilitation and advocacy functions, most of the implementation was appropriate, the highest suitability was in the function as education provider.

Service Coordination, the information in Table 4 illustrated that in the service coordination function, more than $50 \%$ of the case managers performed inter-line coordination functions appropriately, while in the function related to team communication, less than $50 \%$ of the case managers implemented their functions appropriately.

Evaluation from Table 5 above, it could be informed that only a small number of case managers implemented the evaluation function, both patient evaluation and selfevaluation appropriately.
Post-discharge Follow-up, distribution of implementation suitability of post-discharge follow-up plan function in case managers showed that more than half of case managers $(64 \%)$ implemented the function of postdischarge follow-up plan appropriately, and the rest $(33 \%)$ of case managers implemented the functions in appropriately.

\section{Discussion}

Utility assessment is a function, where a case manager is expected to have competence in collecting patients' clinical, social, and financial information by conducting indepth interactions with patients/families and other support units. Utility assessment is a process starting from patient identification,

Table 1 Distribution of Implementation Suitability of Utility Assessment Functions of Case Managers

\begin{tabular}{lllc}
\hline \multicolumn{1}{c}{ Indicator } & \multicolumn{1}{c}{ Criteria } & f & \% \\
\hline Collecting Data & Appropriate & 26 & 72 \\
& Inappropriate & 10 & 28 \\
& Total & 36 & 100 \\
\multirow{4}{*}{ Analyzing Data } & Appropriate & 20 & 56 \\
& Inappropriate & 16 & 44 \\
& Total & 36 & 100 \\
& Atratification of Patient & 19 & 53 \\
& Inappropriate & 17 & 47 \\
& Total & 36 & 100 \\
\hline
\end{tabular}

Table 2 Distribution of Implementation Suitability of Planning Functions of Case Managers

\begin{tabular}{clcc}
\hline \multicolumn{1}{c}{ Indicator } & \multicolumn{1}{c}{ Criteria } & f & \% \\
\hline Setting Goal & Appropriate & 20 & 56 \\
& Inappropriate & 16 & 44 \\
& Total & 36 & 100 \\
Collaborative Decision & Appropriate & 14 & 39 \\
& Inappropriate & 22 & 61 \\
& Total & 36 & 100 \\
\multirow{5}{*}{ Problem Identification } & Appropriate & 21 & 58 \\
& Inappropriate & 15 & 42 \\
& Total & 36 & 100 \\
\hline
\end{tabular}


F Sri Susilaningsih : Implementation of Roles and Functions of Case Managers

Table 3 Distribution of Implementation Suitability of Facilitation and Advocacy Functions of Case Managers

\begin{tabular}{llcc}
\hline \multicolumn{1}{c}{ Indicator } & \multicolumn{1}{c}{ Criteria } & f & \% \\
\hline Education Provider & Appropriate & 30 & 83 \\
& Inappropriate & 6 & 17 \\
& Total & 36 & 100 \\
Protector of Patient & Appropriate & 23 & 64 \\
Rights & & 13 & 36 \\
& Inappropriate & 36 & 100 \\
Soluble & Total & 26 & 72 \\
& Appropriate & 10 & 28 \\
& Inappropriate & 36 & 100 \\
\hline
\end{tabular}

Table 4 Distribution of Implementation Suitability of The Service Coordination Function of Case Managers

\begin{tabular}{clcc}
\hline Indicator & \multicolumn{1}{c}{ Criteria } & f & $\mathbf{\%}$ \\
\hline Team Communication & Appropriate & 17 & 47 \\
& Inappropriate & 19 & 53 \\
& Total & 36 & 100 \\
Inter-line Coordination & Appropriate & 22 & 61 \\
& Inappropriate & 14 & 39 \\
& Total & 36 & 100 \\
\hline
\end{tabular}

Table 5 Distribution of Implementation Suitability of Evaluation Function of Case Managers

\begin{tabular}{rlcc}
\hline Indicator & \multicolumn{1}{c}{ Criteria } & f & \% \\
\hline Patient Evaluation & Appropriate & 13 & 36 \\
& Inappropriate & 23 & 64 \\
& Total & 36 & 100 \\
Self-evaluation & Appropriate & 10 & 28 \\
& Inappropriate & 26 & 72 \\
& Total & 36 & 100 \\
\hline
\end{tabular}

problem analysis, and patient stratification. In qualitative analysis, participants stated that with the appropriate educational experience and background, they could easily carry out utility assessment functions. In carrying out its function a case manager must have qualified knowledge and clinical experiences, and with these clinical competence can analyze and determine the patient needs.

Problem analysis ability is vital for a case manager and is needed since the initial phase of the case management model, namely the problem identification and problem stratification will determine the success of the next phase.

The results of the descriptive analysis on the utility assessment function showed that the case manager function was implemented appropriately by more than half of the number of respondents, the highest percentage of suitability in collecting data. Thus, the implementation of utility assessment functions was carried out, ranging from collecting data/conducting studies, analyzing data, to determining the stratification of patients. The results of this study are in accordance with the study result of Kgasi (2010) that most case managers $(91.7 \%)$ 
F Sri Susilaningsih : Implementation of Roles and Functions of Case Managers

are able to study patients indicate their competence in exploring information and needs of patients and families. Additionally, $79.2 \%$ of case managers are able to build and determine actual and potential problems of patients. The case manager's competence in performing utility assessment functions is certainly inseparable from the organization's readiness to support it, such as the legitimacy of the case manager's position, educational background and work experience, and the strengthening of roles through periodic training.

According to Cesta and Tahan (1998), a case manager must record the clinical competences they have in assessing the needs of patients and families, exploring actual and potential health problems, setting treatment goals and desired outcomes through the nursing process; planning, implementing, evaluating and coordinating other treatments and activities to meet the needs of patients and families, using therapeutic modalities, sophisticated treatments and technology. The previous opinion is appropriate to the practice standard of CMSA (2010) which explains that a case manager must be able to conduct patient assessments in both health and psychosocial aspects, then analyze and calculate patient needs. The utility assessment involves a case manager and patient in identifying issues, strengths, and any information needed during the planning process (SHS, 2013).

Planning is a function, performed by a case manager who is expected to have the competence in drawing up plans for the implementation of patient service management. The planning reflects the feasibility/suitability, quality and cost effectiveness of clinical treatment and patient needs, including discharge planning. Planning is a process starting by determining service goals, making decisions together with teams, patients and families, and identifying other problems that may be faced by patients and families. This was implied by the participants' statement such as how the DPJP (the doctor responsible for the patient) determined the direction of service and patient care in general, and the case manager was responsible for carrying out these provisions. The attitude of the patient and family who fully submitted the service to the officer in charge, the informal discussion process before decision making, and the case manager's efforts to explore every possibility that could be given and might occur to the patient.

The results of the descriptive analysis of the planning function showed that in two indicators namely the determination of objectives and identification of problems, the suitability of implementation was more than $50 \%$, while in the collaborative decision indicator, the suitability of implementation only reached $39 \%$. This was in accordance with the participants' opinions in the interview process which stated that it was difficult for them to sit together because each team member was busy. In addition, participants also stated that often patients and families fully entrusted the service to the officer in charge. This then became difficult when the critical and constructive attitude of the patient and family were needed. Basically, in carrying outpatient services with a case management approach, the case manager works and coordinates collaboratively with various professions, and collaborates with patients and families in establishing interventions (Fraser, Perez, \& Latour, 2015). Therefore, the collaborative decision making including the involvement of patients in this process is very important in planning care. Herein lays the essence of patient-centered care.

The facilitation and advocacy functions include the interaction between MPP and PPA members, payer representatives, and patients/families to maintain continuity of service. Representing the patient interests is at the core of MPP's role; however, this role also reaches out to other stakeholders. MPP advocates for treatment options that can be received after consultation with the DPJP, including a safe return plan. Facilitation and advocacy functions, based on the results of qualitative analysis, are used by the case manager in the process of educating patients and families, protecting the rights of patients, and providing solutions to every problem faced by patients and families. The participants reported how they provided information to patients ranging from admission to discharge from the hospital, monitored the services received by patients both in the room and in 


\section{F Sri Susilaningsih : Implementation of Roles and Functions of Case Managers}

other units, as well as being with patients in solving any problem faced by patients during the treatment.

The results of the descriptive analysis on the facilitation function and advocacy showed that, of the three indicators, namely as education provider, protector of patient rights and solution provider, most of the implementations were appropriate, the highest suitability was in the function as educator, in fact, the implementation of facilitation and advocacy functions as part from the responsibility of a case manager was already functioning.

The responsibility of the case manager is set in the case management practice standard (CMSA, 2010), that the case manager is expected to be able to facilitate any coordination, communication, and collaboration between patients and other stakeholders to achieve treatment goals and maximize the positive outcomes of patients. The above can be achieved if the case manager is always close to the patient by providing a lot of constructive information and education, protecting the patient's rights by direct supervision of the services that the patient gets, as well as providing certainty and the best decision for the patient in every problem encountered. The essence of this process is how to make interactions between the case manager and team members, payers, management, and patients/families to maintain continuity of service. The case manager is also expected to represent the interests of patients by advocating for each treatment option that can be received on each line including the patient's return plan. The technical matters that can be conducted by the case manager on facilitation and advocacy functions are among others (KARS, 2015):

1) Ensure that the patient's examination is appropriate and necessary and is carried out within a predetermined time frame.

2) Communicate with DPJP-PPA regularly during hospitalization and develop an effective working relationship. Helping the DPJP to maintain the expected costs and patient outcomes.

3) Promote the utilization of clinical resources to be effective and efficient.

4) Offering alternative forms of care to patients according to their needs, both because patients are willing to be sent home or need a long term care that is vulnerable to hospital financial regulations.

5) Provide advocacy to patients, enhance collaborative relationship to maximaze the ability of patients and families to make medical decisions.

6) Working with hospital managers and DPJP, provide advocacy on behalf of patients to determine the best service implementations for patients while communicating to patients about the quality facilities available.

7) Providing clinical information to payers and finding the necessary care authorizations. 8) Helping patients and families develop a discharge plan, including coordination with medical services in the community and if necessary, admission to post-treatment care facilities, among other rehabilitation services or skilled care facilities.

Service coordination is a function where the case manager plays a role in coordinating and integrating social services/case management functions into patient care, discharge planning, return processes and coordinate the provision of social services to patients, families, and other people who are important to enable them to deal with the effects of the disease on the patient's family function and to obtain maximum benefit from the health services. In carrying out these functions, the case manager is expected to have competence in establishing good communication with the team and coordinate on each line, such as management, finance, payers, and other units. The participants stated that it was difficult to adjust the time for direct communication as each team member was busy. The two-way communication pattern was used between the information provider through documentation and others. The participants stated that the most important thing was that information was conveyed. Regarding the inter-line coordination, the participants stated it was not difficult because they already knew each other and were facilitated by the room. By coordination is meant here, the clinical and administrative coordination. Other than as a form of anticipation of duplication of actions, coordination is also performed when undesirable things occurred and have not been identified previously. The participants stated that there were certain mechanisms regarding 
F Sri Susilaningsih : Implementation of Roles and Functions of Case Managers

this matter and they just followed the established path. The results of the descriptive analysis of the service coordination function showed that more than $50 \%$ of the case managers performed inter-line coordination functions appropriately, while in the function related to team communication, less than $50 \%$ of the case managers implemented their functions accordingly.

This finding is in accordance with the results of a study by Kgasi (2010) that reports, the majority of case managers are competent to determine appropriate clinical information and coordinate treatment using rapid treatment to determine the patient's needs. An important key aspect in the case management approach is the implementation of holistic and patient-centered care (Fraser, Perez, \& Latour, 2015). Therefore, efforts from the case manager are needed to ensure integrated interventions to reduce service fragmentation. With integrated and intact services, continuity of care can be realized, potential problems at each stage of care can be identified and monitored, and overall services become effective and efficient. Service coordination aims to maintain continuity of service and ensure the fulfillment of patient care needs (KARS, 2015).

Evaluation, results of the qualitative analysis showed that in the evaluation function, each case manager should have the competence in evaluating patients and conducting self-evaluation. Evaluation of patients is usually done indoors and carried out by the case manager in his/her capacity as a nurse; however, evaluation focused on individual patients is still difficult. This was implied in the participant's statement which stated that the case manager admitted that it was still difficult to initiate evaluations together with patients, even though it was done, it was informal. This was due to the difficulty of adjusting and finding the right time with the related parties. As for selfevaluation, participants stated that there was no specific format used by the case manager in reporting the results of activities so that participants found it difficult to see to what extent they were successful in carrying out their the role.

This was supported by results of the descriptive analysis that only a small proportion of respondents carried out the evaluation function appropriately. The evaluation and follow-up process is an important process. This process is not only to see to what extend the plan has been implemented, but also to collect data which can later be reused if the patient is re-treated in a hospital or other service providers. The evaluation process is also an opportunity to share information, experiences and competences among team members during the patient's care period. Evaluation can measure and provide a comparison between achievements with planning, conducting self-evaluation, seeing inequality of service, strengths and opportunities, reflecting every element related to the process, and developing findings during the process into effective practices (SHS, 2013). Evaluation is also expected to show to what extent the case manager has carried out his/her role and functions, thus the performance of each case manager can be assessed. With this assessment, the existence of a case manager can be accounted for and appreciated.

Post-Discharge Follow-up, the role of the case manager in the post-discharge follow-up function is to ensure the continuity of service is safe and timely. The participants stated that they always prepared patients and families before the transition. This was performed by providing counseling to patients and families regarding the patient's condition and how to provide care to patients, as well as ensuring that each element and team was ready when the patient was mobilized. The participants also added that they frequently also helped patients and families by visiting the patient's home when needed. This also aimed to ensure the continuity of patient care when outside the hospital. The result of the descriptive analysis found that service continuity was conducted appropriately by the majority of respondents $(64 \%)$.

The case management process is the manner in which case management functions are performed by case manager, including client identification (screening), assessment, stratifying risk, planning, implementation (care coordination), monitoring, transitioning and evaluation ( Marfleet, Trueman, \& Barber, 2013).

Case management is a collaborative model 


\section{F Sri Susilaningsih : Implementation of Roles and Functions of Case Managers}

and patients are part of every professional device so they are included in the process. Thus, it can be said that case management is a process, and case managers are part of the process (Cohen \& Cesta, 2005). It is essential that the case management system is built, enforced and cultured in advance by the hospital. Some hospitals support each case manager to follow the patient starting from admission to hospital discharge. The transition period or exit can also occur internally and externally. Patients who will be transitioned or discharged from the hospital need clarity and certainty regarding the clinical and administrative conditions and also elevate the social and cultural aspects of the patient when returning home. Thus, careful planning and implementation (SHS, 2013) need to be done. They should focus on realizing and ascertaining the extent of the patient's condition and then developing a follow-up plan to ensure continuity of service. Continuity of service is meant that when patients move or return home, the intensity of care they get is proportional and planned.

\section{Conclusion}

The study on the implementation of the case manager functions at Dr. Hasan Sadikin General Hospital qualitatively identified three function indicators in the utility assessment, namely collecting data, analyzing data and stratifying patients. The quantitative analysis of these functions is implemented appropriately by more than half of the respondents; the highest percentage of conformity is in collecting data functions. In the planning function, three functions are identified qualitatively, namely determining goals, collaborative decisions, and problem identifications. The quantitative analysis of the functions showed two indicators, namely the determination of objectives and identification of problems have reached the conformity of implementation more than $50 \%$, while in the collaborative decision indicator, the suitability of implementation has only reached $39 \%$.

In facilitation and advocacy, functions are identified qualitatively as education providers, protecting the patient's rights and providing solutions. The quantitative analysis of these functions shows that most of the implementations are appropriate; the highest suitability is in the function as education provider. In the context of the service coordinator, team communication and inter-line coordination functions are qualitatively identified. In the quantitative analysis, more than $50 \%$ of case managers have performed the inter-line coordination function appropriately, whereas for functions related to team communication less than $50 \%$ of the case managers have implemented their functions appropriately. In the evaluation function, two functions are identified qualitatively, namely patient evaluation and self-evaluation. Of these two functions, only a small number of case managers have implemented the evaluation functions both patient evaluation and self-evaluation appropriately, and finally, the function of the post-discharge follow-up plan identified the important function of ensuring continuity of service. In this context, more than half of the number of case managers has implemented the appropriate function of the post-discharge follow-up plans.

The initial findings of the case manager function both obtained through qualitative and quantitative studies at this hospital are important as a hospital that pioneers the position of nurse case manager, the identification of functions and their implementations can be information for future evaluation and improvement, therefore the existence of a case manager can truly be a bridge between practitioners/ health professionals and patients, and other stakeholders; coordination of services can be realized, integrity and continuity of patient care can be carried out well, and eventually, the patient gets the best possible of care, patient safety and the quality of care and patient satisfaction can be maintained.

\section{References}

Aeni, W.N. (2014). Pengembangan case manager dalam patient centered care. Jurnal Manajemen Keperawatan, 126-134. 
F Sri Susilaningsih : Implementation of Roles and Functions of Case Managers

AHC. (2016). Case managers need a variety of skills and qualities to succeed. Atlanta: Georgia.

Cesta \& Tahan. (1998). The case managers survival guide: Winning strategies for clinical practice. St. Louis, Misssori, Inc.

CMSA. (2016). Standarts of practice for case management. Available at https://www. miccsi.org/wp-content/uploads/2017/03/ CMSA-Standards-2016.pdf.

Cohen \& Cesta. (2005). Nursing case management: From essentials to advanced practice aplications (4 ${ }^{\text {th }}$ Ed.). New York: Elsevier Mos.

Creswell \& Clark. (2007). Designing and conducting mixed methods research. USA: Sage Publications.

Elwyn, Williams, Roberts, Newcombe, \& Vincent. (2008). Case management by nurses in primary care: Analysis of 73 'Success Stories'. Quality in Primary Care, 75-82.

Fraser K., Perez R., \& Latour C. (2015). CMSA's integrated case managers by case managers. Springer Publishing Co

Huber. (2010). Leadership \& nursing care management. USA: Saunders Elsevier.

KARS. (2015). Panduan penatalaksanaan dokter penanggung jawab pelayanan (DPJP) dan case manager.

Kgasi, K.M. (2010). The role of a case manager in a managed care organisation.
South Africa: Tesis.

Lynn, \& Kelley. (1997). Effects of case management on the nursing contextperceived quality of care, work satisfaction, and control over practice. Journal of Nursing Scholarship, 237-241.

Mamuaja, Tambun, \& Kaunang. (2016). Tanggung jawab perawat sebagai pengelola kasus sesuai UU Keperawatan di Rumah Sakit Umum Daerah Noongan. Riset: Tidak Terpublikasi.

Marleet, F., Trueman, S., \& Barber, R. (2013). National standards of practice for case management ( $3^{\text {rd }}$ Ed.). Case Management Society of Australia \& new Zealand

Morales-Asencio, J.M. (2010). Design of a case management model for people with chronic disease (Hearth failure and COPD). BMC Health Services Research, 10, 324.

SHS. (2013). Case management framework. South Austraia: Departemen for Communities and Social Inclusion. Available at: http://dhs. sa.gov.au/_ data/assets/pdf_file/0005/60593/ Case_management_framework.pdf.

Sugiyono. (2010). Metode penelitian kuantitatif kualitatif \& RND. Bandung: Alfabeta.

Wijono, D. (2008). Manajemen mutu rumah sakit dan kepuasan, pasien prinsip dan praktik. Surabaya: CV Duta Prima Airlangga. 